\title{
Erratum to: Pharmacodynamic effects of EV-077 in patients with diabetes mellitus and coronary artery disease on aspirin or clopidogrel monotherapy: results of an in vitro pilot investigation
}

\author{
Fabiana Rollini - Antonio Tello-Montoliu • Ronakkumar Patel • Andrew Darlington • \\ Ryan E. Wilson · Francesco Franchi · Ana Muñiz-Lozano • Bhaloo Desai · \\ Norbert Bender $\cdot$ Kjell S. Sakariassen · Dominick J. Angiolillo
}

Published online: 8 October 2013

(C) Springer Science+Business Media New York 2013

Erratum to: J Thromb Thrombolysis

DOI 10.1007/s11239-013-0979-8

The author of this article would like to delete the word "only" in the abstract section of the original publication. The sentence in the abstract should read as below:

These data support that EV-077 has additive platelet inhibiting effects on top of standard antiplatelet therapies.

The online version of the original article can be found under doi:10.1007/s11239-013-0979-8.

F. Rollini · A. Tello-Montoliu - R. Patel · A. Darlington .

R. E. Wilson · F. Franchi - A. Muñiz-Lozano · B. Desai ·

D. J. Angiolillo ( $\square)$

University of Florida College of Medicine-Jacksonville,

655 West 8th Street, Jacksonville, FL 32209, USA

e-mail: dominick.angiolillo@jax.ufl.edu

\section{N. Bender}

Evolva SA, Reinach, Switzerland

K. S. Sakariassen

KellSa s.a.s., Biella, Italy 